\title{
Software for calculating the actual lethality of canned food heat treatment processes: development and application
}

\author{
Alexander Zhuk ${ }^{1,{ }^{*},}$ Alexander Stolyanov ${ }^{1}$, Alexander Kaychenov ${ }^{1}$, Lyudmila Kuranova ${ }^{1}$, \\ and Vladimir Grokhovsky ${ }^{1}$ \\ ${ }^{1}$ Federal State Autonomous Educational Institution of Higher Education «Murmansk State Technical \\ University», Sportivnaya str., 13, 183010 Murmansk, Russia
}

\begin{abstract}
The actual lethal effect is traditionally determined by calculating the sum of the lethality rates, given in the reference literature. However, to calculate the heat treatment process F-effect for development new sterilization and pasteurization regimes of canned foods, it becomes necessary to vary the parameters of the base temperature and heat resistance characteristic value of the microorganism test culture. To automate the process of computing, the authors developed the software «Heat treatment process lethality calculation» which calculates the lethality rates, the heating lethal effect and the actual lethal effect (F-effect) values of the canned food heat treatment process. In the paper, the software mathematical calculation formula, graphical user interface and functionality are described. The example of pasteurization conditions selection for canned food «Trout in olive oil with the addition of pickled pineapple» in the tin can No. 2, based on the obtained results from the developed software for calculating the actual lethality of the canned food heat treatment processes, is shown.
\end{abstract}

\section{Introduction}

The process of canned food heat treatment requires finding an optimum between the beneficial and harmful high temperature effects on the product. On the one hand, heat treatment inactivates presented in food products spores, microorganisms and enzymes that have a negative impact on consumer health and product safety. On the other hand, the concentration of unstable to high temperatures nutrients, such as dietary proteins and vitamins (retinol, thiamine, folic acid, ascorbic acid, calciferol and others), decreases [1-3]. Therefore, it is the most important task for researchers to find the optimal heat treatment temperature-time regimes, so-called canned food sterilization (pasteurization) regime [4-7]. It is approved in the established at the territory of the Russian Federation order, provided that the actual lethality level (F-effect) of given technological process exceeds normative value. It means that the product's microbiological indicators meet the industrial sterility regulatory requirements and the product's organoleptic and physicochemical indicators remain at a sufficiently high quality level throughout the product shelf life $[8,9]$. The actual heat

* Corresponding author: zhukaa@mstu.edu.ru 
treatment effect is calculated to account for the lethal effect on microorganisms of all temperatures recorded during the process in the product. The F-effect value is calculated using the product temperature-time dependence in the center of a hermetically sealed canning container and evaluate the canned food suitability for consumption and long-term storage [10]. To determine $F_{f}$ of the thermal process is used the value $z\left({ }^{\circ} \mathrm{C}\right)$. This is the experimentally obtained thermal stability constant for the microorganisms test culture.

The F-effect unit is taken to be an action exerted on a test microorganism by a conditional sterilization or pasteurization process, in which the effect of the base temperature $\left(T_{0}\right)$ lasts for one minute. The magnitude of the actual lethal effect depends on the heat resistance characteristic value $(\mathrm{z})$ of the microorganism test culture in relation to which the heat treatment effect is calculated $[9,11]$.

\section{Rationale}

The actual lethal effect is traditionally determined experimentally by measuring the product temperature in the can center during heat treatment process [12], followed by calculating the actual lethality value using, given in the reference literature, the lethality rates calculated with the following parameters [11]:

- the pasteurization process: the base temperature $\left(\mathrm{T}_{0}\right)$ is assumed to be $80{ }^{\circ} \mathrm{C}$, and the value ( $\mathrm{z}$ ) is 8 or 15 . The calculation is performed for temperatures ranging from $60{ }^{\circ} \mathrm{C}$ to 105 ${ }^{\circ} \mathrm{C}$;

- the sterilization process: the base temperature $\left(\mathrm{T}_{0}\right)$ is assumed to be $121.1{ }^{\circ} \mathrm{C}$, and the value $(\mathrm{z})$ is in the range from 7 to 14 . The calculation is performed for temperatures in the range from $96{ }^{\circ} \mathrm{C}$ to $130{ }^{\circ} \mathrm{C}$.

However, it becomes necessary to vary the parameters $\left(\mathrm{T}_{0}\right.$ and $\left.\mathrm{z}\right)$ to calculate the heat treatment process F-effect for development new or correct existing sterilization and pasteurization regimes of various canned food. To automate the process of computing, the authors of the article developed the software «Heat treatment process lethality calculation», which allows to set arbitrary parameters value $\left(\mathrm{T}_{0}\right.$ and $\mathrm{z}$ ). The software is designed to determine the lethality rates, as well as the heating lethal effect and the actual lethal effect (F-effect) values of the canned food heat treatment process.

\section{Mathematical calculation formula}

The actual heat treatment process lethality value (F-effect) is calculated using the formula:

$$
F=l_{T_{1}^{0}}^{Z} \cdot \tau_{T_{1}^{0}}+l_{T_{2}^{0}}^{Z} \cdot \tau_{T_{2}^{0}}+\ldots+l_{T_{n}^{0}}^{Z} \cdot \tau_{T_{n}^{0}},
$$

where $l_{T_{i}^{0}}^{z}$ - lethality rate for conversion the temperature $T_{i}^{0}$ lethal effect into the equivalent lethal effect value for the base temperature $T_{0} ; \tau_{T_{i}^{0}}$ - temperature $T_{i}^{0}$ action time.

The lethality rate is determined from the equation [11]:

$$
l_{T_{0}}^{Z}=10^{\frac{\mathrm{T}_{\text {prod }}}{\mathrm{T}} \mathrm{T}_{0}}
$$

where $T_{0}$ - temperature adopted as base, ${ }^{\circ} \mathrm{C} ; T_{\text {prod }}$ - temperature of the product for which the lethality rate is calculated, ${ }^{\circ} \mathrm{C} ; Z$ - heat resistance characteristic value of the microorganism test culture, ${ }^{\circ} \mathrm{C}$. 


\section{Software GUI}

The software «Heat treatment process lethality calculation» was created in the free crossplatform visual integrated development environment (IDE) Lazarus on the Object Pascal language. The graphical user interface (GUI) of the main software window is shown on Fig. 1.

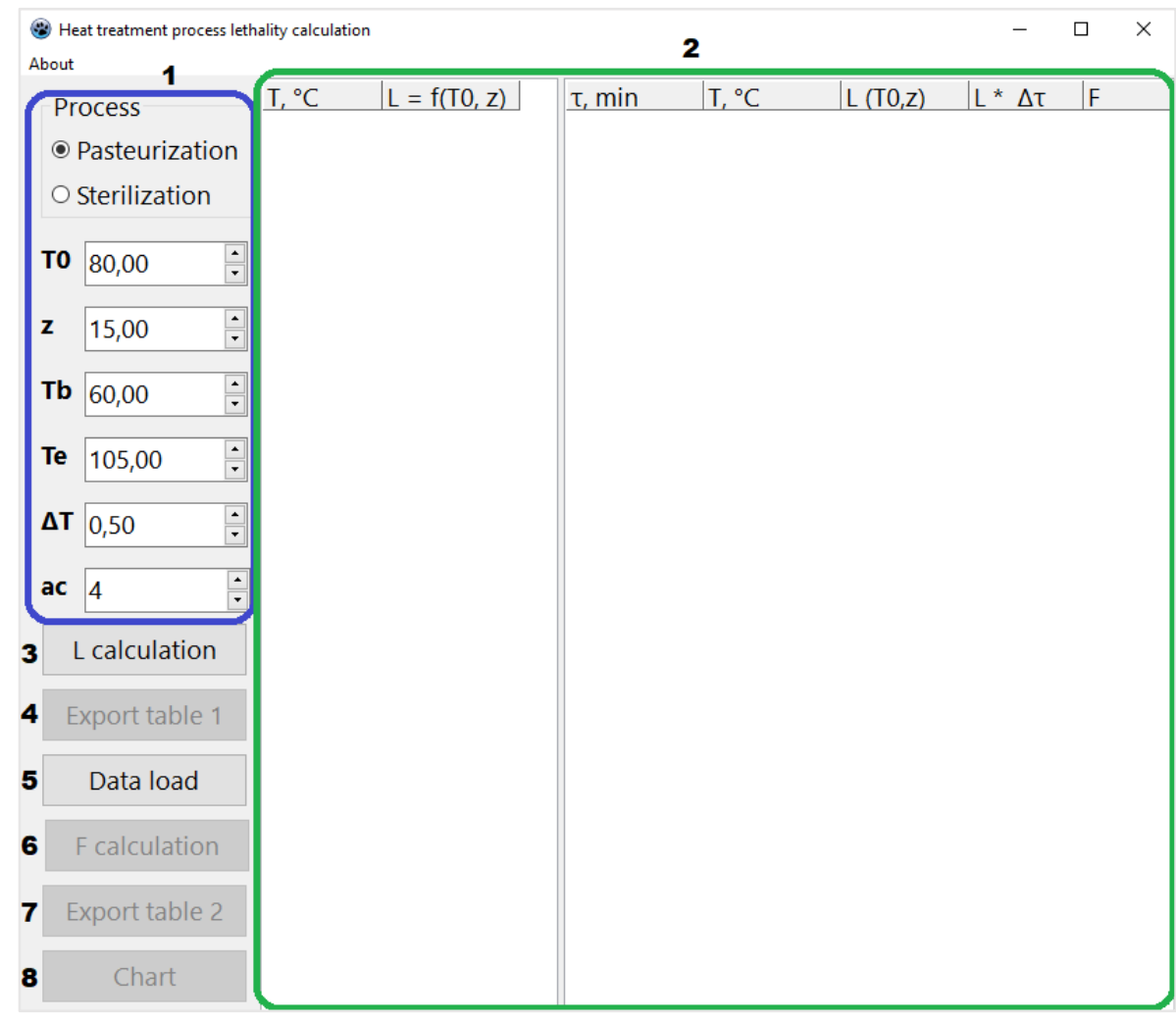

Fig. 1. GUI of the software «Heat treatment process lethality calculation»: 1 - input parameters elements; 2 - tables displaying calculated data; 3 - button «L calculation»; 4 - button «Export table 1»; 5 - button «Download data»; 6 - button «F calculation»; 7 - button «Export table $2 » ; 8$ - button «Chart».

The software window contains the following component groups:

- input parameters elements (position 1 in Fig. 1 ) of the base temperature $\left(T 0,{ }^{\circ} \mathrm{C}\right)$, heat resistance characteristic value of the microorganism test culture $\left(z,{ }^{\circ} \mathrm{C}\right)$, initial $\left(\mathrm{Tb},{ }^{\circ} \mathrm{C}\right)$ and final $\left(\mathrm{Te},{ }^{\circ} \mathrm{C}\right)$ temperatures for calculating lethality rates, temperature change step $\left(\Delta T,{ }^{\circ} \mathrm{C}\right)$ and calculation accuracy ( $a c$, the number of decimal places after the decimal separator);

- two tables (position 2 in Fig. 1) to display the calculating data for the lethality rates and the process actual lethal effect respectively;

- button «L calculation» (position 3 in Fig. 1) for calculating the lethality rates;

- button «Export table 1» (position 4 in Fig. 1) to save lethality rates to a spreadsheet file with the CSV extension;

- button «Data load» (position 5 in Fig. 1) for loading product temperature kinetics data from a CSV file;

- button «F calculation» (position 6 in Fig. 1) to calculate the process actual lethal effect;

- button «Export table 2» (position 7 in Fig. 1) to save the calculation results, including the heating lethal effect values, to a spreadsheet file with the CSV extension; 
- button «Chart» (position 8 in Fig. 1) to open the window for displaying the graphs of process temperature kinetics and F-effect (Fig. 2);

- output field «F» (position 1 in Fig. 2) to display the final F-effect value;

- button «Save to png» (position 2 in Fig. 2) to save graphs of process temperature kinetics and F-effect as an PNG image file.

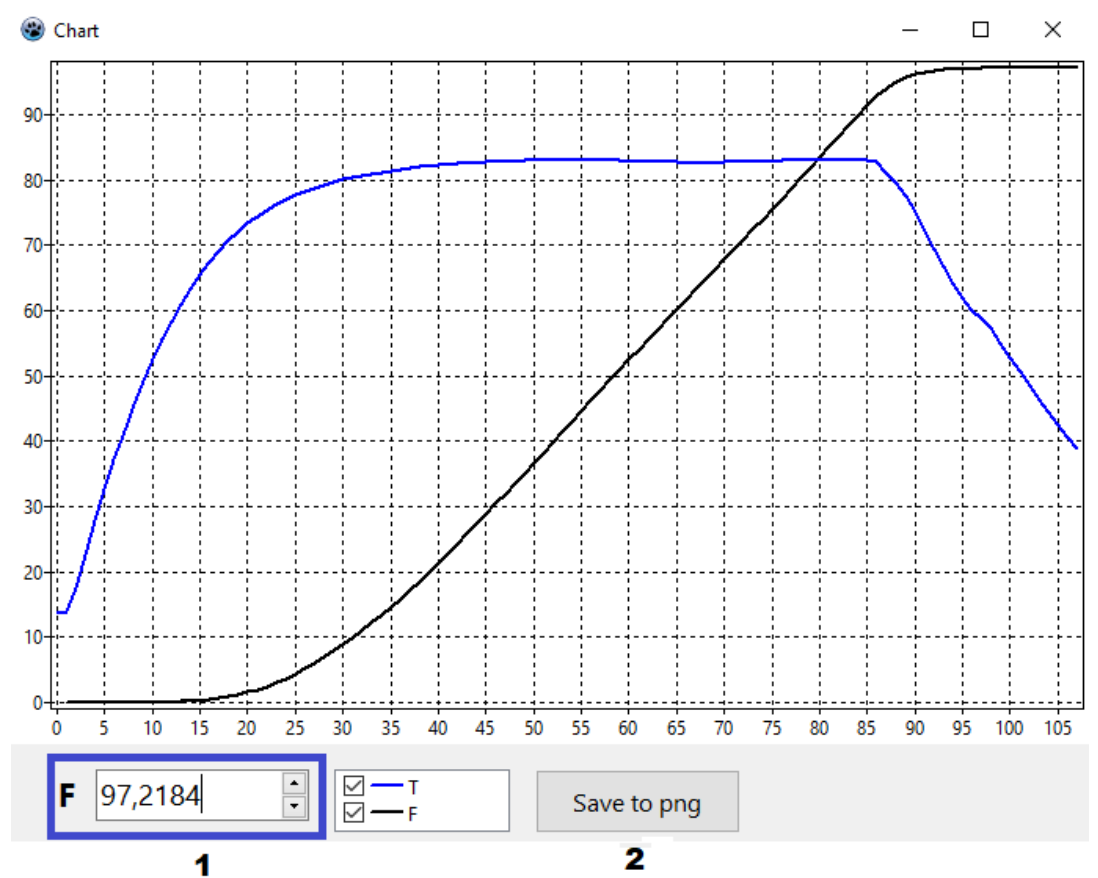

Fig. 2. The window displaying graphs: 1 - output field for the final F-effect value; 2 - button "Save to png".

\section{Software functionality}

The software performs the following functions:

- set arbitrary values of heat resistance characteristic of the microorganism test culture $(z)$ and the temperature adopted as base $\left(T_{0}\right)$, which is necessary when determining the normative lethal effect for the microorganism test culture with thermal stability constant which do not fit into the reference value;

- set the interval (initial and final values) and step of temperature change for which calculation of the lethality rates, the heating lethal effect values and the F-effect values is performed;

- specify the calculation accuracy (the number of decimal places after the decimal separator);

- choose the process type («pasteurization» or «sterilization») to apply standard calculation parameters;

- calculate the F-effect in terms of a given base temperature value $\left(T_{0},{ }^{\circ} \mathrm{C}\right)$ and the heat resistance characteristic value of the microorganism test culture $\left(z,{ }^{\circ} \mathrm{C}\right)$.

\section{Application and results}


A new type of canned food "Trout in olive oil with the addition of pickled pineapple" in tin cans No. 2 (product net weight $170 \mathrm{~g}$ ) was created at the Food Production Technology Department of Murmansk State Technical University. For scientific substantiation and optimization of this canned food pasteurization regime, some work to select the necessary pasteurization regime with the determination of the actual lethality was carried out on the equipment of the canning section of the university educational and experimental workshop. For this purpose, canned food has been made according to four pasteurization regimes in the temperature range from $80{ }^{\circ} \mathrm{C}$ to $95{ }^{\circ} \mathrm{C}$ with the same duration of 60 minutes. The actual lethal effect (F-effect) was established by carrying out a set of thermophysical measurements during the canned food pasteurization, followed by the obtained results mathematical processing in the developed software [13, 14].

The developed program «Heat treatment process lethality calculation» was used to calculate the actual lethality $\left(F_{a}\right.$, conv. $\mathrm{min}$ ) of each pasteurization regime (Table 1$)$, taking into account the value of heat resistance characteristic $z=15$, obtained as a result of preliminary microbiological studies (base temperature $T_{0}=80{ }^{\circ} \mathrm{C}$ ) and experimentally obtained data on the product temperature change during the process using temperature loggers of the TrackSense Pro system (Ellab, Denmark) [12].

Table 1. Actual lethality depending on the pasteurization process parameters of the canned food «Trout in olive oil with the addition of pickled pineapple»

\begin{tabular}{|c|c|}
\hline $\begin{array}{c}\text { Pasteurization process } \\
\text { temperature, }{ }^{\circ} \mathrm{C}\end{array}$ & $\begin{array}{c}\text { Actual lethality }\left(F_{a}\right) \text {, conv. min } \\
\left(z=15^{\circ} \mathrm{C}, T_{0}=80^{\circ} \mathrm{C}\right)\end{array}$ \\
\hline 80 & 52,8925 \\
\hline 85 & 99,9815 \\
\hline 90 & 257,8693 \\
\hline 95 & 466,9099 \\
\hline
\end{tabular}

The normative pasteurizing effect for this type of canned food was preliminarily determined by microbiological studies and equal to $F_{n}=52.921$ conv. minutes [15].

Based on the obtained results from the developed software for calculating the actual lethality of the canned food heat treatment processes (Fig. 3 and 4), pasteurization conditions, that most satisfy the inequality $F_{a} \geq F_{n}$ and the actual lethality at which was almost 100.0 conv. minutes, were selected. Thus, the pasteurization duration for this canned food type was established 60 minutes at the temperature of $85{ }^{\circ} \mathrm{C}$. Therefore, the effective regime of pasteurization and cooling with water in vertical autoclaves of periodic action for canned foods "Trout in olive oil with the addition of pickled pineapple" packaged in tin cans No. 2 is defined as following:

$$
\frac{15-60-20}{85^{\circ} \mathrm{C}}, F_{a}=100.0 \text { conv. min. }
$$




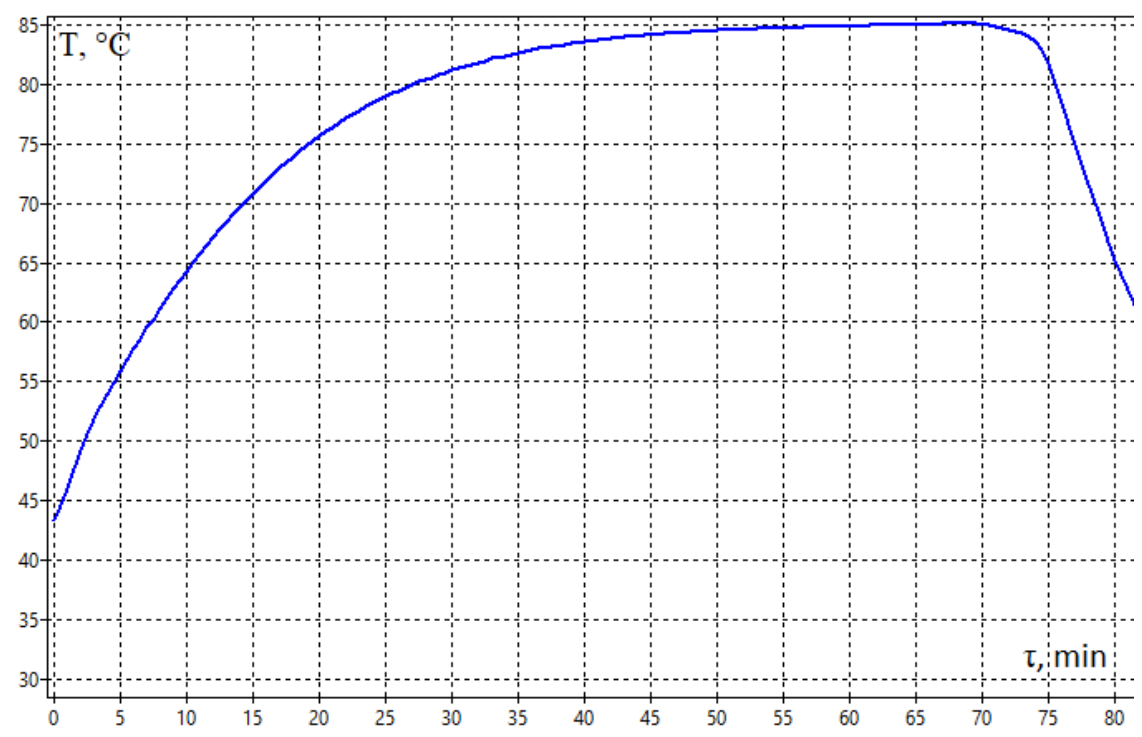

Fig. 3. Temperature dynamics of the effective pasteurization regime for canned food «Trout in olive oil with the addition of pickled pineapple».

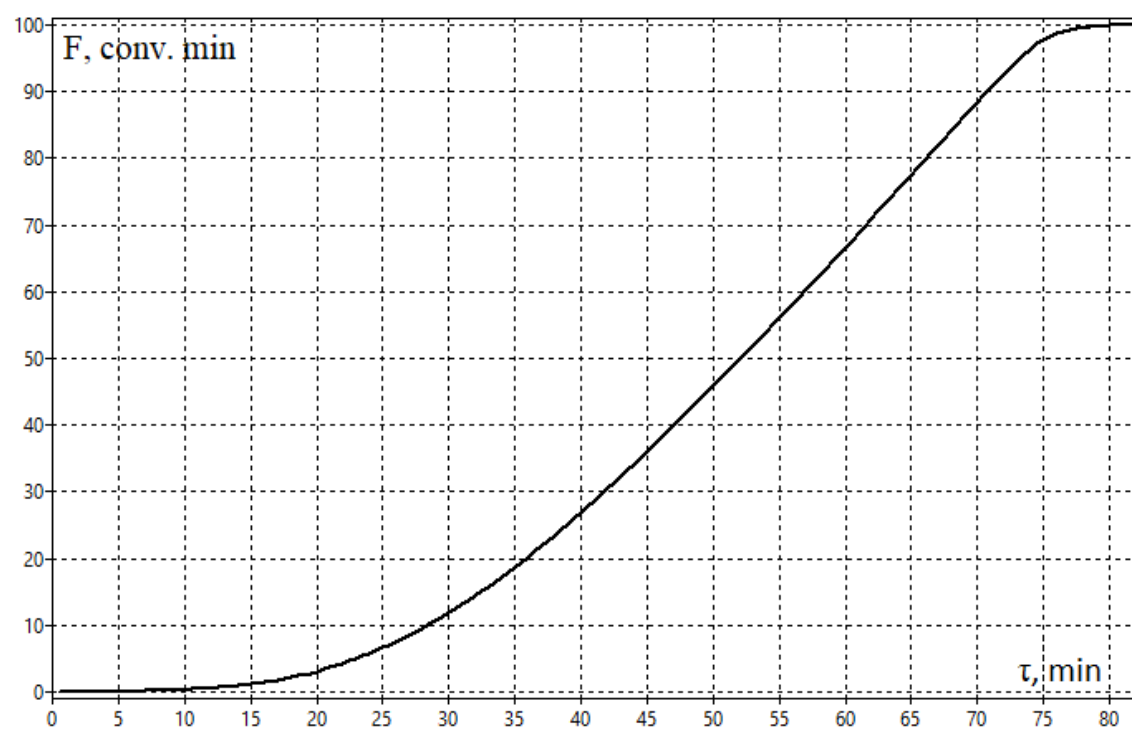

Fig, 4. F-effect dynamics of the effective pasteurization regime for canned food «Trout in olive oil with the addition of pickled pineapple».

\section{Conclusion}

The possibility of the software «Heat treatment process lethality calculation» utilization during the development new or correction existing canned food pasteurization regimes has been proved.

The software «Heat treatment process lethality calculation» can be used as an applied tool in the research on the development and scientific substantiation of products heat treatment 
regimes (sterilization and pasteurization), as well as to control the parameters of the specified technological process in production $[13,14]$.

\section{References}

1. S. Featherstone, A. Complete, Course in Canning and Related Processes 2, 27-42 (2015) doi:10.1016/B978-0-85709-678-4.00002-6

2. T. Deák, Encyclopedia of Food Safety, 219-224 (2014) doi:10.1016/B978-0-12-3786128.00257-2

3. P. J. Fellows, Food Processing Technology, 563-580 (2017) doi:10.1016/B978-0-08100522-4.00011-0

4. A. Abakarov, 2nd International Conference on Biotechnology and Food Science (Singapore: IACSIT Press) 7, 27-31 (2011)

5. A., Stolyanov, et al, IOP Conf. Ser.: Earth Environ. Sci., 403, (2020) doi:10.1088/1755$1315 / 403 / 1 / 012016$

6. A. Abakarov, M. Nuñez, Journal of Food Engineering 115(4), 428-442 (2013) doi:10.1016/j.jfoodeng.2012.02.013

7. Z. Berk, Food Process Engineering and Technology, 399-420 (2018) doi: 10.1016/B978-0-12-812018-7.00017-8

8. F. Silva, et al, Encyclopedia of Food Microbiology, 577-595 (2014) doi:10.1016/B9780-12-384730-0.00404-3

9. R. P. Singh, D. R. Heldman, Introduction to Food Engineering, 421-474 (2014) doi:10.1016/B978-0-12-398530-9.00005-X

10. C. Chen, H. Ramaswamy, Chemical Engineering and Processing: Process Intensification 46(7), 603-613 (2007) doi:10.1016/j.cep.2006.08.003

11. S. D. Holdsworth, R. Simpson, Thermal Processing of Packaged Foods, 125-148 (2016) doi: 10.1007/978-3-319-24904-9_4

12. A. Stolyanov, et al, IOP Conf. Ser.: Earth Environ. Sci., 302, (2019) doi:10.1088/1755$1315 / 302 / 1 / 012031$

13. A. Stolyanov, et al, IOP Conf. Ser.: Earth Environ. Sci., 539, (2020) doi:10.1088/17551315/539/1/012086

14. A. Kaychenov, et al, KnE Life Sciences, 5(1), 437-449 (2020) doi:10.18502/kls.v5i1.6103

15. A. Demid, et al, IOP Conf. Ser.: Earth Environ. Sci., 625, (2021) doi:10.1088/1755$1315 / 625 / 1 / 012014$ 